\title{
Educação pelo esporte na cidade de São Paulo (1920-1936)
}

Education through sports in São Paulo city (1920-1936)

Educación a través del deporte en la ciudad de São Paulo (1920-1936)

\author{
Daniele Cristina Carqueijeiro de Medeiros \\ Universidad de la Republica (Uruguai) \\ https://orcid.org/0000-0001-5493-1618 \\ http://lattes.cnpq.br/6922008080454206 \\ dmedeiros@cup.edu.uy \\ André Dalben \\ Universidade Federal de São Paulo (Brasil) \\ https://orcid.org/0000-0003-1689-6238 \\ http://lattes.cnpq.br/0743727143543352 \\ dalben@unifesp.br \\ Carmen Lúcia Soares \\ Universidade Estadual de Campinas (Brasil) \\ https://orcid.org/0000-0002-4347-1924 \\ http://lattes.cnpq.br/1196961469104964 \\ carmenls@unicamp.br
}

\section{Resumo}

A educação pelo esporte na cidade de São Paulo, entre 1920 e 1936, foi constituída a partir de dois processos distintos. Houve a consolidação de clubes esportivos e, paralelamente, $\mathrm{o}$ Departamento de Educação Física do Estado de São Paulo (DEF-SP) foi criado, em 1931, para gerir ações no âmbito esportivo. Esse artigo analisa o debate entre essas instituições e investiga as disputas engendradas em torno da legitimidade do esporte em São Paulo, especialmente na educação da juventude. Metodologicamente, trata-se de uma pesquisa documental que utilizou como fontes revistas, jornais, anais de congresso e conjunto de leis. $\mathrm{O}$ artigo demonstra que ambos desejaram legitimar a dimensão educativa do esporte em suas diretrizes; entretanto, não houve um diálogo profícuo entre as instituições privadas e públicas frente tal objetivo comum.

Palavras-chave: Educação pelo Esporte. Cultura Física. História da Educação. 


\begin{abstract}
The education through sport in the city of São Paulo, between 1920 and 1936, was constituted of two different processes. There was the consolidation of sportive clubs, and, in parallel, the "Departamento de Educação Física do Estado de São Paulo" (DEF-SP) was created in 1931, to administer actions in sportive sphere. This article analyzes the debate between these institutions and investigate the disputes generated around the legitimacy of São Paulo's sport, especially in youth education. Methodologically, this is a documental research with magazines, journals, congress annals and set of legislation as sources. This article shows that both of them intended to legitimize the sport's educative dimension in their directives; although, there was not a meaningful dialogue between private and public institutions in relation this common objective.
\end{abstract}

Keywords: Education through Sport. Physical Culture. History of Education.

\title{
Resumen
}

La educación a través del deporte en la ciudad de São Paulo, entre 1920 y 1936, fue constituida a partir de dos procesos distintos. Hube la consolidación de los clubes deportivos y, paralelamente, el "Departamento de Educação Física do Estado de São Paulo" (DEF-SP) fue creado, en 1931, para administrar acciones en el ámbito deportivo. Este artículo toma el debate entre esas instituciones e investiga las disputas engendradas alrededor de la legitimidad del deporte en São Paulo, especialmente en la educación de la juventud. Metodológicamente, se trata de una pesquisa documental que utilizó como fuentes revistas, periódicos, anales de congresos y un conjunto de leyes. El artículo demostró que ambos desearon legitimar la dimensión educativa del deporte en sus directrices; sin embargo, no hubo un diálogo proficuo entre las instituciones privadas y públicas frente a tal objetivo común.

Palabras clave: Educación a través del deporte. Cultura Física. Historia de la Educación. 


\section{Introdução}

As duas primeiras décadas do século XX delimitaram um período de grandes transformações na cidade de São Paulo. Pouco a pouco, foram criadas as condições para a consolidação daquela que seria, já ao final dos anos de 1910, a segunda maior cidade do país, atrás apenas da capital federal (QUEIROZ, 2004). Esse acelerado processo de urbanização alterou profundamente os modos de vida, e foi possível perceber a ascensão de divertimentos que engajavam uma inédita cultura física ${ }^{1}$ na cidade, conceito que envolve práticas, relações sociais, econômicas, educacionais, políticas, morais e éticas ligadas aos divertimentos, recreações e esportes, e que foi amplamente divulgado pelos clubes esportivos, sediados às margens dos rios Pinheiros e Tietê, nas primeiras duas décadas do século XX.

A instalação de clubes às margens desses rios, sendo o primeiro deles o Clube Esperia (1899), seguido do Clube de Regatas Tietê (1907), do Esporte Clube Germânia, (1921) e da Associação Atlética São Paulo (1914) foi importante para a consolidação de novas formas de divertimentos em curso, dentre os quais o esporte ocupava lugar central. Há concordância entre historiadores do esporte na afirmação de que os clubes tiveram grande relevância na institucionalização das práticas esportivas (ARNAUD, 1986; VIGARELLO, 2006; DA SILVA, MAZO, 2015). Os rios paulistanos e suas margens atestam essa asserção e inúmeros novos clubes foram inaugurados nas primeiras décadas do século XX, estimulando o desenvolvimento de competições, regatas e provas aquáticas (NICOLINI, 2001).

Na década de 1920, os esportes ganharam visibilidade e importância na capital paulista e passaram a ser considerados como traço de modernização e de urbanidade (SEVCENKO, 2000; RAGO, 2004). Trata-se de um momento de expansão e aceitação, na cidade, tanto de manifestações esportivas mais autônomas quanto de representações mais utilitárias estabelecidas por parte de médicos e educadores, que pretendiam associar a esta prática uma dimensão educativa voltada à regeneração e a preservação da saúde (DALBEN, GOIS JÚNIRO, 2018; DALBEN et. al., 2019; GOIS JÚNIOR, 2013; FRANZINI, 2010).

Foi nesse momento que os clubes tomaram para si a responsabilidade de promover uma cultura física e, mais especificamente, os esportes. Na imprensa diária, assim como nas revistas publicadas pelos clubes, eram divulgadas as proezas atléticas e os resultados das competições, além de um debate acerca dos objetivos educacionais e de preservação da saúde almejados para a prática esportiva na capital paulista. Estas instituições procuravam estabelecer diretrizes, conselhos e prescrições para esta prática, com destaque àquelas realizadas nos rios que banhavam a cidade, com a finalidade de educar o corpo e formar o caráter da juventude. Essas características educacionais eram constantemente ligadas, também, à prática do remo e da natação, esportes considerados salutares e associados, à época, a valores morais e higiênicos (TERRET, 1994; MELO, 1999; 2015).

Ao mesmo tempo, médicos, educadores e cronistas tomaram parte dos debates em curso e reivindicaram a intervenção e o apoio dos poderes públicos na regulamentação e promoção dos esportes (DALBEN, GÓIS JÚNIOR, 2018; GÓIS JÚNIOR, 2013). Surgia a necessidade de um compromisso de autoridades públicas com a administração do esporte no estado paulista, sendo esta prática correntemente interpretada como uma forma de educar a população para o desenvolvimento do vigor físico e da moral, especialmente da juventude (DALBEN et al, 2019). Aqui temos alguns elementos que conduziram à criação do Departamento de Educação Física de São Paulo (DEF-SP) em 1931, instituição que procurou instaurar novas diretrizes para os esportes na cidade.

\footnotetext{
${ }^{1} \mathrm{O}$ conceito de cultura física foi desenvolvido inicialmente por Kirk $(1999 ; 2010)$ e largamente utilizado por Scharagrodsky e colaboradores (2014). No Brasil, esse conceito vem sendo operacionalizado contemporaneamente por alguns autores para analisar a história dos esportes e da educação física, como Moraes e Silva (2011, 2015), Moraes e Silva, Quitzau e Soares (2018), Moraes e Silva e Quitzau (2018) e Montenegro e Soares (2019).
} 
Ao analisarmos a educação pelo esporte na cidade de São Paulo proposta pelos clubes esportivos sediados às margens dos rios Pinheiros e Tietê e pelo DEF-SP, nos valemos de uma compreensão de educação que extrapola as bordas da educação escolar. Entendemos que os processos educativos ocorrem dentro de um quadro que deve considerar as relações sociais, ou seja, que não se desenvolvem exclusivamente no âmbito da escola (KUHLMANN JÚNIOR, LEONARDI, 2017). A partir desta perspectiva indagamos: quais eram as diretrizes elaboradas pelos clubes esportivos para a prática esportiva nos anos 1920? Elas consideravam a dimensão educativa do esporte especialmente voltado à juventude para além dos muros escolares? Existiam diferenças entre as suas proposições e aquelas formuladas pelo DEF-SP a partir de 1931? Como os dirigentes dos clubes receberam a criação de um órgão público especializado no esporte? Quais eram as aproximações e distanciamentos entre os discursos produzidos sobre o esporte pelos clubes e pelo DEF-SP?

O objetivo desse artigo é examinar as disputas entre os clubes de regatas e o DEFSP em torno da legitimidade do esporte paulistano entre 1920 e 1936, mais especificamente, em torno de sua dimensão educativa. A justificativa para este recorte temporal apoia-se no fato de que na década de 1920, surgem na cena clubista conselhos e prescrições acerca de uma cultura física em que o esporte apresenta destaque; já o ano de 1936, recorte final deste artigo, analisa possíveis efeitos do alcance do DEF-SP em torno dos embates de ideias e ideais acerca do esporte paulistano.

O corpus documental desse artigo é composto por distintas publicações dos clubes esportivos paulistanos, como revistas e relatórios; anais do VII Congresso Nacional de Educação; reportagens e notas dos jornais A Gazeta, Correio Paulistano, Correio de São Paulo, Diário Nacional, Folha da Manhã, Folha da Noite; artigo da revista Educação Física, bem como decretos estaduais concernentes ao DEF-SP. O levantamento de fontes foi realizado nos acervos dos clubes Tietê, Associação Atlética São Paulo, Esperia e Esporte Clube Pinheiros ${ }^{2}$, no acervo digital da Assembleia Legislativa do Estado de São Paulo, na hemeroteca digital da Biblioteca Nacional e no acervo on-line do jornal Folha de S. Paulo.

O DEF-SP, atual Secretaria de Esportes do Estado de São Paulo, sofreu ao longo de sua história uma inundação e um incêndio, além de diversas mudanças de endereço, o que comprometeu a conservação de seu arquivo e de sua biblioteca (MASTROROSA, 2003). Parte de suas ações, no entanto, foi narrada pela imprensa diária e especializada e as mudanças sofridas na sua estrutura ao longo do tempo foram registradas pela legislação, ambas fontes utilizadas nesse artigo.

Já a respeito dos clubes, foram utilizadas fontes da imprensa e documentos armazenados em seus acervos. O uso de documentos produzidos e guardados pelos próprios clubes exige cuidados do pesquisador. De um lado, isso se deve porque esses acervos podem ser entendidos como "metáforas do poder" (JOHNES, 2015), ou seja, locais onde são armazenados elementos que corroboram com certa visão da história que os clubes pretendem contar de si mesmos. Como afirma Le Goff (1992, p. 548), fica evidente o esforço para "impor ao futuro - voluntária ou involuntariamente - determinada imagem de si próprios". Por outro lado, há, de forma generalizada, uma falta de cuidados com os materiais relativos ao esporte. De acordo com Johnes (2015), o historiador do esporte encontra muitas vezes dificuldade com arquivos dos clubes, pois muitos deles descartam seus documentos em nome do espaço, ou fecham as portas e não preservam seus materiais. Esse foi o caso, por exemplo, do Clube de Regatas Tietê, analisado nesse artigo ${ }^{3}$.

Em síntese, concordamos com Le Goff (1992, p. 535) e sua afirmação que "os documentos são uma escolha efetuada quer pelas forças que operam no desenvolvimento

\footnotetext{
${ }^{2}$ O Esporte Clube Germânia, um dos clubes investigados nesse artigo, teve seu nome alterado para Esporte Clube Pinheiros na década de 1940, motivado pela obrigatoriedade da nacionalização dos clubes estrangeiros em solo brasileiro proposta pelo governo.

${ }^{3}$ A documentação da antiga biblioteca do clube, que fechou suas portas em 2013, encontra-se em posse do exbibliotecário, André Navarenho.
} 
temporal do mundo e da humanidade, quer pelos que se dedicam à ciência do passado e do tempo que passa". Os documentos, como construções tecidas pelo tempo, estão sujeitos aos seus caprichos, portanto, à destruição, esquecimento e/ou preservação por indivíduos e instituições, tanto de forma intencional quanto acidental.

\section{“És um verdadeiro esportista?" Orientações dos clubes de regatas paulistanos}

Os clubes Esperia, Associação Atlética São Paulo, Tietê e Germânia se instalaram às margens dos rios paulistanos, a maioria deles por iniciativa de grupos de imigrantes ${ }^{4}$, para a prática do remo ou outros esportes. Nas duas primeiras décadas do século XX, o cenário da região da Ponte Grande começava a se alterar: homens e mulheres, em trajes esportivos, desciam rio abaixo a bordo de catraias e barcos de passeio; multidões se avolumavam nas margens do rio para ver os nadadores que disputavam a Travessia de São Paulo à Nado5; treinadores e professores ostentavam seu conhecimento sobre as braçadas da natação em piscinas improvisadas no leito dos rios (NICOLINI, 2001; SEVCENKO, 2000; JORGE, 2006).

A rápida difusão dessas práticas e desses espaços esportivos pela cidade não foi anódina; é certo que uma cultura física se relacionava com características necessárias e, mais do que isso, desejadas para a vida urbana, a vida que São Paulo desenhava para si. Os clubes aqui mencionados rapidamente se dispuseram a conquistar simbolicamente a juventude paulistana, com o intuito de mobilizar, ocupar e, certamente, educar seus associados. Era preciso, portanto, definir de que forma essas práticas seriam realizadas nesses espaços.

A prática esportiva, assim como toda a filosofia que a envolvia, era bastante recente na cidade, e tanto sua dimensão educativa quanto suas bases morais ainda não estavam plenamente solidificadas. Kirk (2008) analisa que, ao longo do século XX, houve uma mudança muito sensível de paradigmas ligados à cultura física. Essa mudança impactou profundamente crenças e valores sobre o corpo, e levou décadas para ser completamente produzida, propagada e incorporada. Logo, a tentativa dos clubes em promover a prática esportiva de acordo com a sua filosofia se traduzia em inúmeros "manuais de instruções", cujo conteúdo procurava demonstrar e esclarecer receios e expectativas que envolviam a prática dos esportes.

Para Vigarello (2002), a cultura física, na qual se incluem as práticas esportivas, não é um fenômeno desinteressado; muito pelo contrário, o esporte surge como um projeto educativo, voltado para a mobilização dos jovens. Bourdieu (2003, p. 141) sublinha que o esporte educava para "a energia, coragem, virtude de líderes [...]". Em vista de tais dimensões que o esporte moderno reúne, é possível inferir que as ideias ali presentes acentuavam os aspectos morais e educativos das atividades desenvolvidas.

Assim, a cultura física promovida pelos clubes voltava-se ao desenvolvimento da juventude de seus associados, cuja centralidade indicava alguns de seus lemas, como no caso do Sport Club Germânia (25 ANOS..., 1924) ao afirmar que: "A força da juventude garante o futuro dos povos" ${ }^{\prime}$. Para os clubes, o fortalecimento do corpo e consequentemente do caráter dos jovens era um dos pilares de suas próprias existências.

\footnotetext{
${ }^{4} \mathrm{O}$ clube Esperia teve sua fundação em 1899, promovida por um grupo de imigrantes italianos que tinha a intenção de fomentar a prática do remo na cidade de São Paulo. No mesmo ano, um grupo de alemães se reuniu para a criação do Sport Club Germania, nascido para a prática de futebol, mas que, após a fundação da sede às margens do rio Pinheiros, passou a se ocupar da prática do remo. Outros clubes relevantes estabelecidos ainda nos primeiros anos do século XX foram o Clube de Regatas São Paulo (dissuadido em 1913), o Clube de Regatas Tietê e a Associação Atlética São Paulo, fundados na mesma região respectivamente em 1907 e 1914 (ZOCCOLI, 1934, p. 48; GALLOTTA, PORTA, 2004).

${ }^{5}$ A Travessia de São Paulo à Nado foi uma prova estabelecida em 1924 e disputada nas águas do rio Tietê, entre a Ponte da Vila Maria e a Ponte Grande até sua extinção, em 1944, dada a insalubridade do rio.

${ }^{6}$ Ver, entre outros, Quitzau e Soares (2010).
} 
Na publicação do clube Germânia encontra-se ainda uma reflexão acerca do que eram considerados como os "temerosos" perigos do mundo moderno e de como eles poderiam influenciar uma juventude fragilizada pela ausência de um trabalho sistemático sobre o corpo. Era, portanto, uma cultura física que, ao educar o corpo, poderia fortalecer o caráter e forjar uma juventude capaz de suportar as tormentas da vida moderna:

Em constante crescimento das demandas impostas aos homens, o mecanismo da vida moderna nos arrasta impiedosamente na sua redemoinhante correnteza. Cruéis, as ondas rugem em jogo horrível e o fraco que não consegue reger o seu barco com nervos fortes e mão firme, precisa afundar irremediavelmente. As ondas tempesteiam para cima e para baixo e ai daquele mimado, cujo corpo débil não consegue resistir ao bater das ondas da vida, que sempre mudam. Já no primeiro choque ele perde o leme, e sem rumo ele deriva em direção ao recife, e desesperado em virtude dos perigos, sem apoio em sua aflição muito antes de ele estar perdido - o valente só saboreia uma vez a morte! (À JUVENTUDE, 1924, p. 14)

É no âmbito dessas ideias que os clubes se autodenominavam como espaços educativos de promoção de uma nova formação física voltada à juventude que os frequentavam, seja nas aulas realizadas em seus espaços (CLUB..., 1920), seja nas disputas esportivas. Essa ação de promoção não se limitava simplesmente à prática de exercícios no interior dos clubes; tratava-se, pelo contrário, de incutir as vantagens morais e higiênicas dos esportes e, acima de tudo, sua capacidade de educar positivamente o caráter dos jovens. Para os clubes, os discursos educativos a respeito da cultura física eram tão ou mais importantes que a própria prática; era necessário delimitar e direcionar aquilo que deveria e poderia fazer parte do escopo dessas associações (ARNAUD, 1986).

Em uma edição da revista do Clube de Regatas Tietê, foram evidenciadas as características moralizantes e éticas do esporte a partir de um questionário a ser respondido pelos associados. De acordo com o questionário, um esportista que não se enquadrasse nas prescrições publicadas não deveria tomar parte das competições promovidas pelo clube:

\author{
ÉS UM ESPORTISTA? \\ Como jogador \\ -Jogas por amor ao esporte? \\ -Jogas para tua turma e não para ti mesmo?[...] \\ -Sabes ganhar sem alarde e perder sem lamurias? \\ Então vaes por um bom caminho para ser esportista \\ Como espectador \\ -Recusas applaudir o bom jogo de teus contrários? \\ -Desejas que ganhem os teus, ainda que não mereçam? \\ [...] \\ Em caso affimativo não és um esportista. Procura chegar a sê-lo. \\ (O QUE É..., 1936, p. 7)
}

Nas publicações do clube Esperia, indicações semelhantes também se fizeram presentes e desejaram demonstrar quais deveriam ser as características d' "O verdadeiro esportista" $(\mathrm{O}$ VERDADEIRO..., 1932, p.6). Os associados que encaravam as competições como o momento mais importante do esporte não seguiam corretamente as diretrizes esportivas do clube. Ao 
contrário, as vitórias e participações nos certames esportivos deveriam ser resultado de esforço e dedicação aos treinamentos:

Há esportistas que praticam os exercicios com satisfacção, são assiduos aos treinos, e tem muita vontade de competir. [...]. Outros, porém, falham sempre aos treinos, denotam pouca vontade, porém nas occasiões de competições, fazem todo os esforços para ganhar. Em geral, estes ultimos desanimam-se facilmente, uma vez que não consigam vencer as provas em que tomam parte (O VERDADEIRO..., 1932, p.6).

Assim, os conselhos e prescrições presentes nas publicações dos clubes eram bastante objetivos: os indivíduos que não treinavam de forma adequada nos esportes selecionados, ainda que talentosos, não deveriam tomar, nas competições, o lugar daqueles que eram perseverantes nos treinos. A dimensão educativa dos clubes expressava-se claramente em uma moral esportiva, na forma como menciona Vigarello (2002), que selecionava aqueles que mais se aproximavam de seus ideais evocados e divulgados.

Para disseminar essa moral esportiva, frequentemente os clubes publicavam reportagens ou notas sobre a necessidade de se transformar o comportamento de seus jogadores ou de sua torcida. Em artigo publicado na revista do Clube Tietê (A TORCIDA...,1934, p.46), o articulista foi enfático em diferenciar a torcida do clube e as torcidas "em geral", que "vão aos campos esportivos gritar desordenadamente e com o intuito de 'aguentar a mão' em caso de necessidade", ou seja, de partir para o confronto físico com o adversário na defesa das cores do clube. A torcida do Tietê, ao contrário, foi descrita como um grupo de moços "distinctissimos, que vão aos campos esportivos incentivar - dentro da maneira mais cavalheiresca e com o maior enthusiasmo e alegria - os "vermelhinhos" " que se batem pelo Tietê" (A TORCIDA...,1934, p.46).

Entretanto, a revista Cho-cho, publicada pelo mesmo clube de forma descontínua durante a década de 1930, cujas opiniões não refletiam as diretrizes oficiais do clube ou de seus dirigentes, evocava o comportamento dos seus torcedores de outra forma. Em artigo publicado em 1931, os editores criticaram o papel da torcida em um campeonato de remo. De acordo com a reportagem, a torcida reclamou de forma incisiva da marcação dos árbitros, que acabaram cometendo erros no momento da chegada das embarcações. Longe de "infundir na torcida ideias pacíficas", os autores avaliaram o papel que eles verdadeiramente deveriam representar durante os torneios:

não podemos deixar de relatar as mancadas de alguns elementos que não compreendem o espirito de coesão que é necessário e abrem a boca somente, para dizer besteiras na maioria das vezes inoportunas e que comprometem a torcida toda.

Devem compreender esses elementos, que é necessário na torcida comunhão de idéas, para não haver mancada, para não dar motivos á críticas e para maior eficiencia da Torcida. (CHO-CHO, 1931, p 3.)

As ações dos clubes com os esportistas e torcedores que não se enquadravam nas regras e condutas consideradas adequadas não se resumiam a advertências: alguns chegaram a ser expulsos do quadro social por não se adequarem nas normas previstas nos estatutos. Foi o caso ocorrido com um nadador do clube Esperia, que violou as regras do clube e foi banido, pelo voto do conselho diretivo. Seguiu-se à notícia o aviso aos demais membros:

\footnotetext{
${ }^{7}$ Modo como os esportistas do Clube de Regatas Tietê eram chamados, por conta da cor de seus uniformes.
} 
Uma agremiação esportiva deve primar antes de tudo pela disciplina, pelo bom comportamento, e pela educação de seus componentes. Não deve ser obstáculo para tal o valor esportivo. Todos os associados do clube são eguaes pelos estatutos. Seja qual for o valor esportivo de seus elementos, todos são obrigados aos mesmos deveres (A ELIMINAÇÃO...1929, p.9).

A "educação de seus componentes", conforme enfatiza a nota supracitada, expressa uma moral presente em tais clubes que desenvolviam largamente o remo e a natação, dois esportes associados fortemente a aspectos higiênicos e moralizantes. Na revista do clube Esperia enfatizava-se que "a disciplina da natação fôrma-vos o caracter" (NETTO, 1928). Para o escritor, a natação educava jovens intrépidos, animados, imperturbáveis, independentes e cheios de iniciativa. Essas características apontadas como sendo inerentes ao esporte expressavam o empenho dos clubes em educar seus associados, aliado às diretrizes morais difundidas a respeito dessas práticas.

O escrutínio de nossas fontes indica, claramente, a tentativa dos clubes em legitimar as práticas da cultura física, com acentuado destaque aos esportes, realizadas em seus espaços, especialmente por meio da ênfase em sua dimensão educativa e em seu caráter positivo e moralizante. Mais do que promover esportes ao lado de outras atividades, os clubes desejavam tomar para si as ideias circulantes acerca dessas práticas e de suas representações, ou seja, desejavam protagonizar os discursos relacionados à cultura física e afirmar o caráter educativo das atividades desenvolvidas em seu interior. É desse modo que ora prezavam pela manutenção de práticas que consideravam adequadas, ora repreendiam e regulavam o comportamento de seus associados. A ascensão e a relativa incorporação de uma cultura física na cidade de São Paulo, certamente recebeu a influência das ideias e ideais propalados e promovidos pelos clubes na tentativa de legitimá-la. Cabe agora entendermos como essas ideias e ideais foram colocados à prova com a criação de um Departamento de Educação Física no Estado de São Paulo.

\section{“O Departamento de Educação Physica poderá der util ás sociedades esportivas?”: embate de ideias entre clubes esportivos paulistanos e o DEF-SP}

Os clubes possuíam plena consciência da dimensão educativa presente em suas ações. Pautavam-se, assim, em ideais sobre os benefícios morais e higiênicos dos esportes para balizar aquilo que era promovido em seu interior em favor de seus associados, e que consideravam ser imprescindível aos esportistas. Ao divulgarem esses ideais, os clubes se auto intitulavam grandes incentivadores da cultura física, especialmente dos esportes, e capazes de educar a juventude que os frequentava.

Para isso, produziram um conjunto de diversificados meios de divulgação de suas ideias, sublinhando, assim, seu próprio modo de se ver e de como desejaram ser vistos. É possível afirmar que tais associações se muniam dos discursos correntes a respeito dos benefícios do esporte, da prática de exercícios e da educação física escolar, e, dessa forma, promoviam suas próprias definições de cultura física.

A rivalidade estampada nas competições realizadas entre os clubes de regatas era apenas aparente. De fato, o que havia entre as agremiações era uma grande união, pois compartilhavam um sentimento de abandono do poder público. Assim, caberia apenas a si mesmas a tarefa de manter vivas as práticas esportivas da cidade: 
Os grêmios nauticos, através de mil dificuldades e contando unicamente com as modestas contribuições de seus associados, construíram pistas, piscinas, barco-escolas, salas de esgrima, quadras de tennis, e uma porção de outras realizações verdadeiramente notáveis. (CLUBS, 1935, p.4)

Ao mesmo tempo em que exaltavam suas próprias realizações nesse campo, os clubes não deixavam de criticar a falta de ação do poder público no gerenciamento e difusão das práticas esportivas. Em artigo que narrava em tom heroico seus feitos ao longo de 33 anos de existência, o clube Tietê assim registrou suas críticas à falta de investimentos e incentivos por parte da administração pública:

Hoje o Tietê é um grande clube. Não tão grande como deveria ser. Mas a culpa disso não cabe aos seus iniciadores e tão pouco aos continuadores da obra, mas sim aos governos passados que se descuidaram dos efeitos benéficos que traz a cultura física a um povo, relegando-a para um segundo plano, quando não taxando os clubes com pesados impostos. (33 ANIVERSÁRIO..., 1940, p.2)

Na década de 1930 os clubes analisados já se encontravam bem estabelecidos e com grande número de associados. Esse foi o momento d' "O progresso dos esportes" (STEMPNIEWSKI, 1935, p.1), uma vez que, conforme o autor, as praças esportivas dos clubes, outrora "verdadeiros cemitérios", agora viviam apinhadas de jovens que se valiam dos benefícios educativos e morais dos esportes. Ainda de acordo com o autor, foi primordial para essa conquista a "propaganda intelligente e efficiente das directorias dos clubes, da imprensa e dos próprios esportistas", o que excluía, certamente, um incentivo da administração pública.

No momento em que o Esperia inaugurava sua piscina, em 1933, outras críticas foram tecidas ao poder público que, na visão do clube, não promovia adequadamente a educação física dos brasileiros. Cabia, portanto, à iniciativa particular a promoção de avanços nesse campo, como era o caso da construção de uma piscina:

Fechados na ignorância de tão importante problema, que é a educação physica dos brasileiros, o nosso governo nada tem feito em beneficio do esporte. No emtanto causa satisfação ver como a iniciativa particular, tão em contraste com o trabalho official, toma vultor e se torna realidade nos clubes de São Paulo. Há em todos elles uma actividade febril de progresso, um ideal puro, patriótico e bom. (A PISCINA..., 1933, p.8)

No que se refere à administração pública, o DEF-SP foi criado em janeiro de 1931 com a finalidade de orientar, dirigir e fiscalizar a prática esportiva no Estado de São Paulo (SÃO PAULO, 1931a). A sua criação esteve relacionada com uma série de debates, realizados na imprensa paulistana durante a década de 1920, sobre a importância do esporte para educar a mocidade brasileira (DALBEN, GÓIS JÚNIOR, 2018). Ainda que a notícia da sua criação tenha sido acompanhada por notas de congratulações, inclusive do Clube Esperia (DEPARTAMENTO..., 1931), não faltaram manifestações de protestos e demonstrações do receio quanto à ingerência que a nova repartição poderia proporcionar aos clubes (SILVEIRA, 1931; O PROBLEMA..., 1931, AMARAL, 1931). Os maiores protestos vieram da Associação Paulista de Esportes Athleticos (APEA) (NÃO SE DEVE..., 1931, FABBRI, 1931a, 1931b, 1931c), responsável também por encaminhar ofício solicitando que o DEF-SP intercedesse junto aos poderes públicos, pleiteando a redução no valor dos impostos que incidiam sobre as 
competições esportivas, o que gerou caloroso debate na imprensa paulistana (O DR. ANTONIO..., 1931; PLEITEANDO..., 1931, A ENTREVISTA..., 1931).

Após reuniões com as federações esportivas o DEF-SP elaborou uma proposta para criar um regime especial de tributação para os clubes de modo a isentá-los da cobrança do imposto municipal sobre os divertimentos públicos. Encaminhada para o Secretário de Educação e Saúde Pública, a proposta elencava uma série de razões, sobretudo morais, para diferenciar os torneios esportivos de outros divertimentos, os quais incluíam peças de teatro, concertos musicais, bailes, sessões de cinema, apresentações circenses, entre outros. O principal argumento empregado foi que "as competições de educação física são sempre de caráter realmente educativo, o que só raramente ocorre com relação aos divertimentos públicos, que podem ser até deseducadores" (A QUESTÃO..., 1931, p.6). A estratégia empregada se utilizava da dimensão educativa dos esportes, tão exaltada pelos clubes ao longo de anos, para diferenciá-los dos divertimentos públicos e eximi-los da cobrança do imposto. A ação, no entanto, não surtiu efeito e as divergências com as federações esportivas, somada à reduzida verba que dispunha e o pequeno número de funcionários, acabaram impossibilitando que o DEF-SP atuasse na regulamentação e fiscalização da prática esportiva dos clubes (O ANNIVERSARIO..., 1932).

O DEF-SP foi criado como um departamento autônomo dentro da estrutura da Secretaria do Interior, logo depois transformada em Secretaria da Educação e da Saúde Pública (SÃO PAULO, 1931b). Em fevereiro de 1933, durante a reforma da educação promovida por Fernando de Azevedo, ele foi extinto e no seu lugar foi criado o Serviço de Educação Física, subordinado agora ao Departamento de Educação. De acordo com Mastrorosa (2003, p.39), com a submissão do antigo DEF-SP ao Departamento de Educação, "o projeto anterior que visava a autonomia do campo da Educação Física é substituído por um outro que entende a Educação Física como parte da Educação". A nova repartição, apesar de manter os antigos funcionários, contava com uma estrutura organizacional completamente diferente e passava a priorizar a educação física escolar e não mais a regulamentação dos esportes praticados nos clubes. De acordo com Soares (2017, p.81), "Fernando de Azevedo tentou implantar uma reforma semelhante à que havia instituído no Rio de Janeiro". A sua proposta era de vincular a higiene escolar ao campo da educação e não ao da saúde. Ao Serviço de Educação Física, por exemplo, estava previsto que se ocupasse de "organizar e dirigir a educação física para as classes especiais de debeis físicos" (SÃO PAULO, 1933a), atribuição inexistente no antigo DEF-SP.

Embora os clubes tenham relevância na produção de novos sentidos atribuídos à cultura física (KIRK; TWIGG, 1994), especialmente na disseminação de práticas esportivas entre os habitantes das cidades, a escola foi também um importante campo de ação de políticas voltadas à educação do corpo (SOARES, 2011; SOARES, 2014; ROCHA, 2003). Em 1933, por ocasião da criação do cargo de professor de ginástica em um ginásio oficial no interior do Estado de São Paulo, fato que fez com que houvesse pela primeira vez um concurso público para esse cargo, a revista do clube Esperia promoveu um debate sobre a atuação da administração pública estadual a respeito da cultura física (A INICIATIVA..., 1933, p.8). Apesar de o referido artigo ter elogiado a atitude do governo, foram elencados pelo clube alguns problemas sobre a atuação do DEF-SP. O primeiro questionamento foi que, em seus primeiros anos de existência, o Departamento tinha elaborado diversos projetos, mas poucos deles saíram do papel. A segunda crítica foi direcionada a incorporação do referido órgão ao Departamento de Educação. De acordo com o artigo, essa ação seria responsável por confirmar que o poder público se preocupava com a organização da cultura física somente no ambiente escolar. Longe de afirmar que o incentivo à educação física nos estabelecimentos de ensino era algo negativo, o artigo reclamava a falta de propostas de auxílio aos clubes: 
Agora que esse Departamento foi annexado à Diretoria do Ensino [Departamento de Educação], temos a impressão de que officialmente, só se cogitará da cultura physica nos estabelecimentos de ensino. E vai dahi que os clubes - que em S. Paulo são em grande numero e contam com um verdadeiro exercito de sócios - continuarão a não merecer a attenção dos poderes públicos. Não nos referimos ás ajudas materiaes, mas tão simplesmente aos apoios Moraes, e ao bafejo no tocante a parte technica, de um lado, e de outro á organização, ou melhor á racionalização na pratica dos esportes. (A INICIATIVA...1933, p.8)

É importante relatar que as alterações efetivadas pela reforma empreendida por Fernando de Azevedo desagradaram não apenas os representantes do clube Esperia, como os próprios funcionários do antigo DEF-SP. Segundo artigo publicado na revista Educação Física:

Essa reforma não consultava os interesses superiores da fisiocultura, tanto que o próprio diretor do Departamento de Educação, dr. Fernando de Azevedo, modificou as bases do Serviço de Educação Física, por iniciativa e proposta dos seus chefes, antigos funcionários do extinto Departamento [de Educação Física], mas nem assim logrou dar-lhe a necessária eficiência. E dêsse modo, durante mais de um ano, permaneceu praticamente inativa a organização oficial da educação física em São Paulo (HISTÓRICO..., 1936, p.40).

As modificações nas bases do Serviço de Educação Física foram efetivadas em abril de 1933, com a publicação do Código de Educação, principal documento da reforma de Fernando de Azevedo (SÃO PAULO, 1933b). Apesar das alterações promovidas, o Serviço de Educação Física permaneceu inativo, não havendo na imprensa paulistana nenhuma referência às suas ações nesse período. Pouco mais de um ano depois, quando Azevedo já não ocupava mais o cargo de diretor do Departamento de Educação, uma nova modificação foi promovida e o antigo DEF-SP foi restabelecido. A legislação que decretou o seu reestabelecimento destacava em tom crítico que a sua extinção "restringiu a ação do Govêrno, [...] que deveria ser a mais ampla possível" (SÃO PAULO, 1934a). Três meses depois, um novo regulamento foi promulgado, e o DEF-SP passou então a conjugar a regulamentação da prática esportiva com a responsabilidade pela educação física escolar (SÃO PAULO, 1934b).

Ainda que o projeto de Azevedo tivesse perdido força, o DEF-SP passaria a conferir maior atenção à educação física escolar a partir de 1934, se comparado à 1931. Em 1935, por exemplo, por ocasião do VII Congresso Nacional de Educação, Arne Enge, funcionário do departamento, apresentou as ações e propostas concebidas na formação superior de professores especializados em educação física para atuarem na educação infantil paulista (ENGE, 1935). Entre os anos de 1934 e 1936, o DEF-SP concentrou seus esforços na criação e funcionamento da Escola Superior de Educação Física de São Paulo ${ }^{8}$, responsável por formar profissionais que atuariam tanto nas escolas quanto nos clubes. Nesse mesmo período o DEF-SP atuou ainda na implementação do controle médico-esportivo ${ }^{9}$, na exigência de registro anual em sua sede de todos os clubes paulistas e na fiscalização das competições esportivas que cobrassem ingresso.

\footnotetext{
${ }^{8}$ Sobre a criação da Escola Superior de Educação Física, atual Escola de Educação Física e Esporte da Universidade de São Paulo, conferir Góis Júnior (2017), Gnecco (2005) e Mastrorosa (2003).

${ }^{9} \mathrm{O}$ controle médico-esportivo instaurado pelo DEF-SP a partir de 1934 consistia na realização de medições antropométricas do corpo dos esportistas paulistas e registro em fichas individuais. Ver a respeito Vimeiro-Gomes e Dalben (2011).
} 
O restabelecimento do DEF-SP e a publicação do seu novo regulamento em 1934 não passaram incógnitos, tendo gerado novas críticas por parte dos clubes e federações. Carlos de Campos Sobrinho (técnico de natação do Clube de Regatas Tietê) destacou, em entrevista ao jornal carioca Diário da Noite, que o novo regulamento tinha alarmado os representantes dos clubes por temerem a instauração de entraves para as suas ações, sobretudo com a criação de novas taxas e despesas (ROSA, 1934a). A preocupação dos clubes já não era mais com o fato do DEF-SP se ocupar da educação física nas escolas, mas com a possibilidade de "onerar sua[s] despesa[s] com novas taxas, difficultar a situação financeira dos clubes com exigencias" (A FINALIDADE..., 1934, p.5).

Frente aos receios dos clubes esportivos paulistanos, o DEF-SP os convocou para uma nova reunião. Na ocasião, o seu diretor, Antonio Bayma, afirmou que o Departamento "não seria órgão de intromissão na vida dos clubes, mas centralizador das iniciativas particulares a que reconheceu todos os esforços em benefício do esporte. Affirmou a necessidade de coordenar esses esforços dispersos" (A FINALIDADE..., 1934, p.5). Ou seja, o diretor do DEFSP reiterava o discurso que afirmava serem os clubes os principais incentivadores do esporte em São Paulo, mas combatia aquele que posicionava o Departamento como um agente contrário ao desenvolvimento de suas ações. O seu intento era de reposicionar discursivamente o DEF$\mathrm{SP}$, afirmando a repartição pública como um agente centralizador e facilitador dos esforços empreendidos pelos clubes e não mais como um entrave.

$\mathrm{Na}$ reunião, Bayma esclareceu que o novo regulamento não impunha novas taxas aos clubes e afirmou que considerava pesados os impostos que incidiam sobre os esportes (A FINALIDADE..., 1934). Aos participantes, apresentou a proposta de redução de tributos formulada no ano de 1931 e propôs que os clubes e federações enviassem relatórios com dados numéricos e sugestões para que o DEF-SP pudesse fazer uma nova representação junto ao governo estadual (COGITANDO..., 1934). Bayma explicitou ainda que, nesse momento, o DEF-SP faria uma distinção de tratamento entre os "esportes propriamente ditos e exibições esportivas com fitos comerciais" (A FINALIDADE..., 1934, p.5), ou seja, os esportes considerados como educativos e aqueles "praticados com finalidades exclusivas de lucros individuaes ou de empresas" (ROSA, 1934b, p.4). Entre os classificados como comerciais encontravam-se o futebol, modalidade que maiores recursos financeiros aportavam aos clubes e que tinha sido profissionalizado no ano anterior, e o boxe, modalidade de luta moralmente condenada por diversos setores da sociedade. Segundo Rosa (1934b, p.4), "a maioria dos [...] esportes poderão ser considerados modalidades educacionais", com exceção daqueles que tinham se profissionalizado. Ao que tudo indica, a nova proposta procuraria isentar de impostos somente as modalidades esportivas categorizadas pelo DEF-SP como educativas.

$\mathrm{Na}$ edição seguinte à reunião, a revista Esperia publicou artigo em que propunha colaboração com o Departamento, caso houvesse a possibilidade de auxílio mútuo aos clubes. Pode-se ler no artigo que "se S. Paulo tem progredido no campo esportivo deve-o ao enthusiasmo dos esportistas dedicados que militando nas innumeras aggremiações, conseguiram despertar o gosto do público pelos esportes" (DEPARTAMENTO..., 1934, p.5). Assim, se o Departamento tivesse o interesse em articular parcerias com os clubes de regatas, "[neles] encontrar[ia] a melhor boa vontade para o bom desempenho de seu mandato" (DEPARTAMENTO..., 1934, p.5).

Novas reuniões foram realizadas entre os representantes do DEF-SP, dos clubes e das federações esportivas, mas na terceira, a Federação Paulista de Natação já não se fazia presente, tampouco a APEA. Na ocasião, o diretor do DEF-SP apresentou uma proposta, a ser levada ao governo do estado, de redução de $22 \%$ para $8 \%$ do imposto cobrado sobre as competições esportivas, com sua reversão integral para custear o controle médico-esportivo que seria implementado pelo Departamento (VAE SER..., 1934). A falta de recursos financeiros para a efetivação das ações previstas para o DEF-SP constituía-se, de fato, como um problema desde 
a sua criação em 1931 (DALBEN et al, 2019). A proposta apresentada na reunião visava solucioná-lo, ao menos no que se referia à implementação do controle médico-esportivo, ao mesmo tempo em que reduziria uma parcela dos impostos que incidiam sobre os clubes.

Em artigo publicado no jornal Correio de São Paulo, o jornalista Mário Miranda Rosa criticou a falta de engajamento dos clubes nos debates, expondo assim o pouco interesse despertado nas entidades esportivas pelas reuniões organizadas pelo DEF-SP (ROSA, 1934c). Ao que tudo indica, a dificuldade encontrada pelo DEF-SP em se afirmar como representante dos clubes e federações perante o governo se dava justamente por ele próprio compor a administração pública. Com a intenção de deixar registrado o pouco envolvimento dos clubes nas reuniões e estabelecer para a história futura a sua versão, Rosa (1934c, p.4) previa que:

Assim é que se esqueceram os nossos esportistas de que futuramente e isto é inevitável - estarão os esportes gritando contra a falta de auxilio do Governo, e que é pouco beneficiar o esporte apenas com a organização do controle médico. Pedirão praças de esporte, pedirão piscinas, pedirão verbas para participação de grandes torneios mundiaes, pedirão, enfim, tantas e tantas outras coisas, de que no momento não se lembram, imbuidos com a perspectiva de que tudo lhes faltarão. Não, certamente, sem o seu proprio esforço, affirmariamos.

$\mathrm{Na}$ edição seguinte da revista Esperia, datada de outubro de 1934, novo artigo foi publicado sobre o DEF-SP. Iniciava-se com uma pergunta feita no próprio formulário a ser preenchido para o registro anual dos clubes: "O Departamento de Educação Physica poderá ser útil ás associações esportivas?" Para responder à pergunta, os autores do artigo argumentaram não ser possível perceber de que forma o Departamento seria capaz de transformar as práticas realizadas no clube, já que elas tinham, desde o princípio, a proposta de favorecer o desenvolvimento da cultura física:

No tocante a orientação que o Departamento poderá vir a imprimir á prática dos esportes como educação physica, pouco de útil vemos para os clubes. Estes, na medida do possível e de accordo com as proprios possibilidades e necessidades, já deram á pratica dos exercicios esportivos tudo o que se lhes poderia exigir para que esses exercícios fossem factores de educação physica (O DEPARTAMENTO...,1934, p.7).

É possível perceber que, na visão dos clubes, eles eram os verdadeiros responsáveis pela disseminação do esporte na cidade e por transformá-lo em uma prática educativa; logo, o trabalho do DEF-SP nunca seria completo sem uma ação conjunta com essas instituições. Embora assumissem que a ideia de uma prática esportiva orientada para a educação da juventude fosse o intuito prioritário de ambos, os clubes queriam mais do que o reconhecimento dos serviços por eles prestados nesse âmbito. Para essas instituições, a colaboração ideal entre clubes e DEF-SP não seria a elaboração de um programa comum de divulgação e disseminação de práticas esportivas para os jovens, e sim a diminuição de taxas pagas ao Estado. Com relação a uma proposta do DEF-SP orientar a prática dos esportes nos clubes, o artigo era enfático: “[...] será preciso considerar que uma orientação única, generalizada para todos os clubes, não poderá ser efficiente, uma vez que os clubes têm varias categorias, nem todos apresentam as mesmas condições physicas e de sanidade (O DEPARTAMENTO..., 1934, p.7)”.

$\mathrm{O}$ artigo apresentou ainda pessimismo em relação às ações do DEF-SP pelo fato dele não poder "contrariar os interesses materiais da administração publica em beneficio dos clubes" (O DEPARTAMENTO..., 1934, p.7), ao se referir a cobrança de impostos. E concluiu que o 
DEF-SP, “emanação que é do governo, estará tolhido de pleitear uma medida que é contrária aos interesses da administração publica. Evidencia-se, pois, que o Departamento não poderá ser útil aos clubes" (O DEPARTAMENTO..., 1934, p.7). Para os autores do artigo, se o Departamento não procurasse meios de auxiliar financeiramente os clubes com a isenção de impostos, ele estaria fadado ao fracasso, uma vez que se encontrava dependente deles para pôr em prática as ações estabelecidas no seu regulamento:

O Departamento nunca poderá centralizar as atividades esportivas. Terá que se soccorrer da organização dos clubes; da existência destes nunca poderá prescindir para realizar a sua tarefa. [...] os clubes, evidentemente, não quererão se submetter ao controle e vezes ás imposições do Departamento (O DEPARTAMENTO..., 1934, p.7).

O Departamento representava a materialização das ações governamentais que procuravam atender às solicitações médicas, educativas e da imprensa, que requeriam veementemente uma ação do Estado em relação às práticas da cultura física, e especialmente do esporte, na cidade de São Paulo (DALBEN, GÓIS JÚNIOR, 2018). Embora suas ações estivessem em consonância com aquelas dos clubes em relação às demandas morais, higiênicas e educativas do esporte, não houve, a princípio, uma aproximação entre clubes e o DEF-SP. Os clubes consideravam que a ação do DEF-SP não deveria ameaçar seu protagonismo e sua dimensão educativa na difusão do esporte na cidade. O DEF-SP seria mais eficiente na redução de impostos ou na promoção de aportes financeiros e materiais. Segundo as fontes analisadas, é possível captar um primeiro momento onde se constata uma aproximação entre o DEF-SP com a educação física escolar, vista pelos clubes como um entrave ao desenvolvimento dos esportes. Essa constatação fica secundarizada frente a questão financeira, considerada, posteriormente, o maior problema entre essas instituições e seus ideais a respeito da difusão do esporte.

Com um começo acanhado, nem sempre provido de grandes realizações, foi ao longo das décadas de 1920 e 1930 que os clubes viveram seu esplendor e promoveram, de fato, uma grande renovação nas práticas de exercícios físicos e esportes na cidade de São Paulo, especialmente nos seus rios e margens. As críticas realizadas ao DEF-SP se constituíam menos de reclamações contra o seu programa de estabelecimento e divulgação de uma cultura física e mais contra a falta de incentivo financeiro aos clubes. Ao mesmo tempo, é possível perceber que essas críticas procuravam também reafirmar que a promoção dos esportes na cidade de São Paulo era responsabilidade dos clubes, especialmente os de regatas.

\section{Conclusão}

No estudo aqui realizado, foi possível verificar que os clubes esportivos procuraram expressar, de modo claro, a dimensão educativa das diversificadas práticas realizadas em seu interior. Uma pedagogia do corpo e da saúde foi ali desenvolvida indicando qual a forma "correta" de praticar esportes e, mais amplamente, exercícios físicos. Havia uma grande disputa de significados atrelados à cultura física que se solidificavam naquele momento na cidade de São Paulo, e os clubes procuravam estabelecer as bases morais daquilo que imaginavam ser o "verdadeiro esportista". Uma cultura física totalmente inédita e distinta daquilo que havia anteriormente nascia na cidade e mudanças profundas nos sentidos e significados atribuídos aos esportes, enfatizando seu caráter educativo e moralizador, eram promovidos nesses espaços.

Entretanto, os clubes não se limitavam a determinar a prática esportiva de seus próprios associados, mas, e de acordo com o conjunto de documentos produzidos e aqui analisados, se auto intitulavam os verdadeiros porta-vozes de uma educação pelo esporte na cidade. Essa 
percepção de si foi colocada à prova com a criação do DEF-SP, em 1931, órgão oficial criado para orientar, dirigir e fiscalizar a prática esportiva em São Paulo.

O DEF-SP desejou estabelecer um possível diálogo com os clubes com a finalidade de construir, conjuntamente, bases educativas e morais por meio da prática esportiva na cidade. Havia uma concordância entre eles sobre às demandas morais, higiênicas e educativas do esporte; no entanto, não houve uma união entre os clubes e o DEF-SP por conta do receio de que o departamento poderia roubar-lhes o protagonismo e pioneirismo na divulgação e promoção do esporte na cidade. Para os clubes, esta aproximação tinha finalidade prática e se restringia à solicitação de aumento de suas receitas, alcançado pela diminuição de impostos pagos ao município ou de aportes financeiros e materiais.

A educação pelo esporte na cidade de São Paulo entre 1920 e 1936 deixou traços bem marcados no diversificado e numeroso conjunto de documentos produzidos pelas instituições (pública e privadas) que examinamos. Ao manusear essas tantas páginas, nos aproximamos da compreensão acerca da educação dos moradores da cidade, forjada para além dos muros escolares e, neste sentido, do papel exercido pelos clubes na promoção e divulgação de uma cultura física na cidade de São Paulo. Do mesmo modo, também pudemos captar as ideias de educação por parte das ações do DEF-SP que, como órgão público, começou a atuar também em uma forma específica de educação do corpo que começava a afirmar-se no Brasil, a educação física realizada no âmbito escolar. Em concordância, ambos procuravam estabelecer projetos educativos: seja de uma educação física voltada para as crianças nas escolas, seja de uma educação pelo esporte voltada para a juventude nos clubes.

\section{Referências}

25 ANOS Sport Club Germânia. 25 Jahre - Sport Cub Germania 1899-1924, São Paulo, 1924.

33ํAIVERSÁRIO do Clube Tietê. Tietê - Orgão oficial do C.R. Tietê, São Paulo, ano 1, n. 4, p. 2, abr./mai. 1940.

A ELIMINAÇÃO de Virgilio Martini. Esperia - Revista Mensal do Club Esperia, São Paulo, v. 1, n. 6/7, p. 9, mar./abr. 1929.

A ENTREVISTA do dr. Antonio Bayma ao Diário Nacional: uma carta do diretor do Departamento de Educação Physica. Diário Nacional. São Paulo, 21 ago. 1931, p. 6.

A FINALIDADE do Departamento de Educação Physica é collaborar com os clubes. Correio de São Paulo, São Paulo, 21 ago. 1934, p.5.

A INICIATIVA official em pról da educação physica. Esperia - Revista Mensal do Club Esperia, São Paulo, v. 5, n. 60, p. 8, out./nov. 1933.

À JUVENTUDE. 25 Jahre - Sport Club Germania 1899-1924, São Paulo, p. 14, 1924.

A PISCINA do Club Esperia. Esperia - Revista Mensal do Club Esperia, São Paulo, v. 5, n. 55, p. 6, maio 1933 .

A QUESTÃO dos impostos esportivos. Folha da Noite, São Paulo, 29 out. 1931, p. 6.

A TORCIDA do Tietê. C.R. Tietê - Revista Commemorativa da Inauguração da Piscina, São Paulo, p. 46, 3 jun. 1934. 
AMARAL, F. Pompêo. Grandiosidades. Folha da Manhã, São Paulo, 28 jan. 1931, p. 13.

ARNAUD, Pierre. Pratiques et pratiquants: les transformation de la sociabilité sportive. L'example de Lyon et du départament du Rhône entre 1850 et 1914. In : ARNAUD, Pierre ; CAMY, Jean. La Naissance du mouvement sportif associatif en France: sociabilités et formes de pratiques sportives. Lyon : Presses Universitaires de Lyon, 1986.

BOURDIEU, Pierre. Como é possível ser esportivo? In. BOURDIEU, Pierre. Questões de sociologia. Lisboa: Fim de século, 2003.

CHO-CHO: Folha clandestina no seio do Club de Regatas Tietê. São Paulo, n. 4, 2 ago. 1931.

CLUB Athletica S. Paulo. Parte Sportiva. In: CLUB ATHLETICA S. PAULO. Relatório esportivo Club Atletica S. Paulo. São Paulo: [s. n.], 1920. p. 9.

CLUBS esportivos. Esperia - Revista Mensal do Club Esperia, São Paulo, v. 7, n. 5, p. 4, ago./set. 1935.

COGITANDO de desafogar o esporte. Correio Paulistano, São Paulo, 22 ago. 1934, p.8.

DA SILVA, Carolina Fernandes; MAZO, Janice Zarpellon. Uma história das instrumentalidades do esporte no campo do associativismo esportivo em Porto Alegre/RS. Movimento, Porto Alegre, fev. 2015, p. 377-389. DOI: https://doi.org/10.22456/1982$\underline{8918.48215}$

DALBEN, André, et al. Criação do departamento de educação física do estado de São Paulo (1925-1932). Cadernos de Pesquisa, São Paulo, v. 49, n. 171, p. 264-286, jan./mar. 2019. DOI: https://doi.org/10.1590/198053145203

DALBEN, André; GÓIS JÚNIOR, Edivaldo. Embates esportivos: o debate entre médicos, educadores e cronistas sobre os esportes e a educação da juventude (Rio de Janeiro e São Paulo, 1915-1929). Movimento, Porto Alegre, v. 24, p. 161-172, 2018. DOI: https://doi.org/10.22456/1982-8918.76349

DEPARTAMENTO de Educação Physica. Esperia - Revista Mensal do Club Esperia, São Paulo, ano 6, n. 6, p. 5, jul./ago.1934.

DEPARTAMENTO de Educação Physica: officios de congratulações enviados ao sr. secretario do Interior. Folha da Manhã. São Paulo, 31 jan. 1931, p. 1.

ENGE, Arne. A organização dos serviços de Departamento de Educação Física do Estado de São Paulo. In.: Congresso Nacional De Educação, 7., 1935, Rio de Janeiro, Anais... Rio de Janeiro, ABE, 1935, p. 61-69.

FABBRI, Honorino. Encerrando a questão. Folha da Manhã, São Paulo, 14 fev. 1931a, p. 6.

FABBRI, Honorino. Errou o alvo. Folha da Noite, São Paulo, 16 fev. 1931b, p. 6.

FABBRI, Honorino. Resposta necessária. Folha da Manhã, São Paulo, 8 fev. 1931c, p. 17. 
FRANZINI, Fàbio. Esporte, cidade e modernidade: São Paulo. In: Victor Andrade de Melo. (Org.). Os Sports e as Cidades Brasileiras: Transição dos Séculos XIX e XX. Rio de Janeiro: Apicuri, 2010, p. 49-70.

GAllOTTA, Brás Ciro; PORTA, Paula. Cronologia: 1890-1954. In: PORTA, Paula (Org.). História da cidade de São Paulo. São Paulo: Paz e Terra, 2004, p.603-617.

GNECCO, José Roberto. Reforma Universitária e a USP: a integração da Escola de Educação Física em 1969. Tese (Doutorado em Educação) - Universidade de São Paulo, São Paulo, 2005.

GÓIS JUNIOR, Edivaldo. A institucionalização da educação física na imprensa: a construção da Escola Superior de Educação Physica de S. Paulo na década de 1930. Movimento, Porto Alegre, p. 701-714, jun. 2017. DOI: https://doi.org/10.22456/1982-8918.69223

GÓIS JUNIOR, Edivaldo. O esporte e a modernidade em São Paulo: práticas corporais no fim do século XIX e início do XX. Movimento, Porto Alegre, v. 19, p. 95-117, 2013. DOI: https://doi.org/10.22456/1982-8918.37530

HISTÓRICO do departamento de educação física do estado de São Paulo, de 1931 a 1934. Revista de Educação Física, Rio de Janeiro, v. 5, n. 31, p. 40, maio 1936.

JOHNES, Martin, Archives and historians of sport. The International Journal of the History of Sport, v. 32, n. 15, p. 1784-1798, 2015. DOI: https://doi.org/10.1080/09523367.2015.1108307

JORGE, Janes. Tiete, o rio que a cidade perdeu: o Tiete em São Paulo 1890-1940. São Paulo: Alameda, 2006.

KIRK, David. Los futuros de la Educación Física: la importancia de la cultura física y de la «idea de la idea» de Educación Física. In: AA. VV. Actas V Congreso Asociación Española de Ciencias del Deporte. León: Universidad de León. (CD-R), 2008.

KIRK, David. Physical Culture, Physical Education and Relational Analysis. Sport, Education and Society, v.4, n.1, p.63-73,1999. DOI: https://doi.org/10.1080/1357332990040105

KIRK, David. Physical education futures. Nova Iorque: Routledge, 2010. DOI: https://doi.org/10.4324/9780203874622

KIRK, David; TWIGG, Karen. Constructing Australian bodies: social normalization and school medical inspection (1909-1919). Journal of Australian Studies, v.18, n.40, p. 57-74, 1994. DOI: https://doi.org/10.1080/14443059409387166

KUHLMANN JÚNIOR, Moysés; LEONARDI, Paula. História da educação no quadro das relações sociais. História da Educação, Santa Maria, v.21, n.51, p.207-227, abr. 2017. DOI: https://doi.org/10.1590/2236-3459/66163

LE GOFF, Jacques. História e memória (2a ed.). Campinas: Editora Unicamp, 1992. 
MASTROROSA, Adriano. Departamento de Educação Física, Escola Superior de Educação Física e Associação dos Professores de Educação Física: o ordenamento da Educação Física no Estado de São Paulo no início da década de 1930. 2003. Dissertação (Mestrado em Educação) - Pontifícia Universidade Católica de São Paulo, São Paulo, 2003.

MELO, Victor Andrade. Enfrentando os desafios do mar: a natação no Rio de Janeiro do Século XIX. Revista de Historia (USP), v. 172, p. 299-334, 2015. DOI: https://doi.org/10.11606/issn.2316-9141.rh.2015.98755

MELO, Victor Andrade. O mar e o remo no Rio de Janeiro do século XIX. Estudos Históricos (Rio de Janeiro), Rio de Janeiro, n.23, p. 41-60, 1999.

MONTENEGRO, Nara Romero; SOARES, Carmen Lúcia. Cultura physica e vida ao ar livre: a reinvenção do litoral de fortaleza (1920-1940). Movimento, Porto Alegre, p.e25092, dez. 2019. DOI: https://doi.org/10.22456/1982-8918.88925

MORAES E SILVA, Marcelo. Comportamentos urbanos e Esportes: contribuições para a esportivização do Turfe e da Pelota Basca em Curitiba (1899-1905). Licere (Centro de Estudos de Lazer e Recreação. Online), v. 18, p. 86-115, 2015. DOI: https://doi.org/10.35699/1981$\underline{3171.2015 .1130}$

MORAES E SILVA, Marcelo. Novos modos de olhar outras maneiras de se comportar: a emergência do dispositivo esportivo da cidade de Curitiba (1899-1918). 2011. 227f. Tese (Doutorado) - Faculdade de Educação, Universidade Estadual de Campinas, 2011.

MORAES E SILVA, Marcelo; QUITZAU, Evelise Amgarten. A cultura física na cidade de Curitiba: a emergência de uma pedagogia corporal (1899-1909). Revista de Ciencias Sociales - Arturo Prat, v. 41, p. 275-296, 2018.

MORAES E SILVA, Marcelo; QUITZAU, Evelise Amgarten; SOARES, Carmen Lucia. Práticas educativas e de divertimento junto à natureza: a cultura física em Curitiba (1886-1914). Educação e pesquisa, v.44, p.178293, 2018. DOI: https://doi.org/10.1590/s1678$\underline{4634201844178293}$

NÃO SE DEVE confundir prática esportiva com cultura physica. Folha da Manhã, São Paulo, p. 14, 4 fev. 1931.

NETTO, Coelho. Palavras de Coelho Netto, que devem ser sempre lembradas. Esperia - Revista Mensal do Club Esperia, São Paulo, ano 1, n. 1, p. 1, set. 1928.

NICOLINI, Henrique. Tietê: o rio do esporte. São Paulo, SP: Phorte, 2001.

O ANNIVERSÁRIO do Departamento de Educação Physica. Folha da Manhã, São Paulo, p.14, 30 jan. 1932.

O DEPARTAMENTO de Educação Physica poderá ser util ás sociedades esportivas?. Esperia - Revista Mensal do Club Esperia, São Paulo, v. 6, n. 7/8, p. 7, set./out.1934.

O DR. ANTONIO Bayma julga absurdos os impostos que oneram os clubes esportivos de S. Paulo. Diário Nacional, São Paulo, p. 6, 20 ago. 1931. 
O PROBLEMA de nossa cultura physica. Folha da Manhã, São Paulo, 27 jan. 1931, p. 14.

O QUE É necessário para poder ser um esportista? Tietê - Revista dos Tietanos, São Paulo, v. 1, n. 6, p. 7, mar. 1936.

O VERDADEIRO esportista. Esperia - Revista Mensal do Club Esperia, São Paulo, v. 4, n. 42, p. 6, abr. 1932.

PLEITEANDO reducção de taxas: um officio da Apea ao Departamento de Educação Physica do Estado. A Gazeta, São Paulo, 20 ago. 1931, p. 7.

QUEIROZ, Suely Robles Reis de. Política e Poder Público na cidade de São Paulo: 1899-1954. In: PORTA, Paula (Org.). História da cidade de São Paulo. São Paulo: Paz e Terra, 2004.

QUITZAU, Evelise Amgarten; SOARES, Carmen Lúcia. “A força da juventude garante o futuro de um povo": a educação do corpo no Sport Club Germania (1899-1938). Movimento (ESEFID/UFRGS), Porto Alegre, v.16, n.3, p.87-106, maio 2010. DOI: https://doi.org/10.22456/1982-8918.10554

RAGO, Margareth. A invenção do cotidiano na metrópole: sociabilidade e lazer em São Paulo, 1900-1950. In: PORTA, Paula (Org.). História da cidade de São Paulo. São Paulo: Paz e Terra, 2004.

ROCHA, Heloisa Helena Pimenta. A higienização dos costumes: educação escolar e saúde no projeto do Instituto de Hygiene de São Paulo. Campinas: Mercado de Letras; FAPESP, 2003.

ROSA, Miranda. A reducção de impostos. Correio de São Paulo, São Paulo, 19 set. 1934c, p.4.

ROSA, Miranda. Em torno da entrevista de Carlos de Campos Sobrinho. Correio de São Paulo, São Paulo, 15 ago. 1934a, p.4.

ROSA, Miranda. Esporte e comércio. Correio de São Paulo, São Paulo, 23 ago. 1934b, p.4.

SÃO PAULO (Estado). Decreto n. 4.855, de 27 de janeiro de 1931. Crea o Departamento de Educação Physica do Estado de São Paulo. São Paulo, 1931a.

SÃO PAULO (Estado). Decreto n. 4.917, de 03 de março de 1931. Transforma a Secretaria de Estado dos Negócios do Interior em Secretaria de Estado da Educação e da Saúde Pública e da outras providencias. São Paulo, 1931 b.

SÃO PAULO (Estado). Decreto $n^{o}$. 5.828, 04 de fevereiro de 1933. Reorganiza a Diretoria Geral do Ensino, transformando-a em Departamento de Educação; transfere para este os serviços do Departamento de Educação Fisica, que fica extinto; crea o Serviço de Higiene e Educação Sanitaria Escolar, o Fundo Escolar, a Bolsa de Viagem ou de Estudos, o Museu Central e o Conselho de Educação, 1933a.

SÃO PAULO (Estado). Decreto $n^{o}$. 5.884, 21 de abril de 1933. Institue o Código de Educação do Estado de São Paulo, 1933b. 
SÃO PAULO (Estado). Decreto $n^{\circ}$. 6.440, 16 de maio de 1934. Restabelece o Departamento de Educação Física, 1934a.

SÃO PAULO (Estado). Decreto $n^{o}$. 6.583, 1 de agosto de 1934. Aprova o regulamento do Departamento de Educação Física, 1934b.

SCHARAGRODSKY, Pablo Ariel. Palabras preliminares. In: SCHARAGRODSKY, Pablo Ariel. Miradas médicas sobre la cultura física en Argentina (1880-1970). Buenos Aires: Prometeo, 2014.

SEVCENKO, Nicolau. Orfeu extatico na metropole: São Paulo, sociedade e cultura nos frementes anos 20. São Paulo: Companhia das Letras, 2000.

SILVEIRA, J. Dias. Uma crítica antecipada. Folha da Manhã, São Paulo, 5 fev. 1931, p. 14.

SOARES, Carmen Lucia. As roupas nas práticas corporais e esportivas: a educação do corpo entre o conforto, a elegância e a eficiência (1920-1940). 1a.. ed. Campinas: Autores Associados, 2011. v. 1. 180p.

SOARES, Carmen Lucia. Educação do corpo. In: GONZÁLES, Fernando Jaime; FENSTERSEIFER, Paulo Evaldo. (Org.). Dicionário Critico de Educação Física. $3^{\mathrm{a}}$ ed.Ijui: Unijui, 2014, v. 1, p. 219-225.

SOARES, Márcia Guedes. As políticas de educação do Serviço Sanitário de São Paulo entre a República Velha e o Estado Novo. 2017. Dissertação (Mestrado em Educação) - Universidade Estadual de Campinas, Campinas, 2017.

STEMPNIEWSKI, E. O progresso dos esportes. Esperia - Revista Mensal do Club Esperia, São Paulo, v.7, n.5/6, p. 1, jun./jul. 1935.

TERRET, Thierry. Naissance et diffusion de la natation sportive. Paris: Editions L'Harmattan, 1994.

VAE SER feita representação ao governo pleiteando a reducção para $8 \%$ dos impostos sobre torneios esportivos. Correio de São Paulo, São Paulo, 18 set. 1934, p.5.

VIGARELLO, Georges. "S'entraîner". In: VIGARELLO, Georges; CORBIN, Alain; COURTINE Jean- Jacques. Histoire du corps: les mutations du regard - Le $\mathrm{XX}^{\mathrm{ème}}$ siècle. Paris: Seuil, pp. 164-197, 2006.

VIGARELLO, Georges. Du jeu ancien au show sportif: la naissance d'un mythe. Paris: Éditions Seuil, 2002.

VIMIEIRO-GOMES, Ana Carolina; DALBEN, André. O controle médico-esportivo no Departamento de Educação Física do Estado de São Paulo: aproximações entre esporte e medicina nas décadas de 1930 e 1940. História, Ciência, Saúde: Manguinhos, Rio de Janeiro, v. 18, n. 2, p. 321-336, jun. 2011. DOI: https://doi.org/10.1590/S0104-59702011000200004

ZOCOLLI, C. O Tietê de hoje e de amanhã. Revista do Clube de Regatas Tietê. n.48, jun. 1934. 